\title{
Governing education quality—challenges of perspective and methodology
}

\author{
Guri Skedsmo $^{1,2} \cdot$ Stephan Gerhard Huber $^{1}$
}

Published online: 3 November 2017

(C) Springer Science+Business Media, LLC 2017

Data-based knowledge has become a vital element of governing and managing educational quality (Ozga et al. 2011). The data is produced by different types of instruments, such as external and internal forms of evaluations and assessments at the individual, program, organisational or system level, or even combined and put together to create order in complex systems and as a basis for strategic target setting. An important aspect of data-based knowledge is linked to establishing transparency and holding institutions, groups and individuals to account on important performance indicators. Moreover, data-based knowledge increases expectations of actors at various levels, such as politicians, the media, educational authorities, educational leaders, teachers, students and their parents, to interpret results, mediate and make decisions, which is not a straightforward process (Spillane 2012; Mausethagen, Prøitz and Skedsmo 2017). However, the increased demand for this type of knowledge requires paying attention to developing sound evaluation instruments and methodologies to "produce" accurate and trustworthy data. With these increasing expectations and demands, we would argue that great responsibility follows.

This issue of EAEA includes four contributions regarding how to govern education quality by considering evaluation from external and internal perspectives, as well as methodological concerns with respect to the evaluation design, approach and the choice of variables to include in the analysis, and not least instrument development.

Guri Skedsmo

guri.skedsmo@ils.uio.no

$\triangle$ Stephan Gerhard Huber

stephan.huber@phzg.ch

1 Institute for the Management and Economics of Education, University of Teacher Education Zug, Zug, Switzerland

2 Department of Teacher Education and School Research, University of Oslo, Oslo, Norway 


\section{Articles in this issue of EAEA 4/2017}

In the first article, Kemethofer, Gustafsson and Altrichter compare the effects of socalled new inspection models in the Austrian state of Styria and Sweden, as they are perceived by school leaders in the respective countries. In addition, they investigate principals' perceptions of the mediating processes in the inspection models implemented in the two countries, where they also consider the evaluative and governing contexts in which the inspection models are embedded. The two countries have somewhat different traditions of school inspection, and both countries' inspection models were transformed and modernised around 2007/2008. In Styria, the model introduced represents more standardised procedures and allows for comparison across schools. In Sweden, the inspection model moved towards more control-oriented evaluation and a higher degree of accountability pressure around the same time, a move reinforced by the Education Act and Ordinance of 2011. The data that forms the basis for the analysis were gathered through three quantitative surveys sent out online to school leaders over a period of 3 years within the EU project Impact of School Inspection on Teaching and Learning. An important finding is that different mediating mechanisms change in terms of influence throughout an inspection cycle. Whilst setting expectations is generally an important mechanism for the school leader prior to the inspection, accepting feedback seems to be crucial after the inspection has taken place. Interestingly, the effects of the school inspection by these two mediating mechanisms, as perceived by the school leaders, play out differently in a low-stake context such as Austria compared to Sweden, where there is more at stake for the school leaders, depending on the inspection results.

In the second article, Ehren and Godfrey explore how the external accountability of a Multi-Academic Trust (MAT) in England, in other words a network of schools and the trust, changes over time. A MAT is the result of government policies in England, which aim to support schools by creating school-to-school partnerships and formal networks between stronger and weaker schools categorised according to inspection results (OFSTED). The schools are all publicly funded, and the networks are run by a Trust (Board of Directors). The authors find alignment between the internal quality control in the MAT and the OFSTED frameworks. At the same time, vertical or topdown forms of accountability do not support the creation of inter-organisational networks, as they are not sufficiently flexible to effect change. Ehren and Godfrey therefore suggest network accountability as an alternative, where the methodology of the Inspectorates of Education aims to capture the mechanisms and conditions that describe the functioning and performance of the network in a standardised way. Additional accounts from local stakeholders provide data to be used for local interpretation and meaning constructions among the key actors involved, and thereby enable the necessary adaptations to context and network characteristics.

In the third article, Ackerman and Egalite look critically at methodologies used to evaluate the effectiveness of charter schools in the USA. In particular, they analyse the model used by the Stanford Center for Research on Education Outcomes (CREDO) in a national charter school study first published in 2009 and then updated with a larger sample in 2013. Based on statewide data from Florida for the period 2001 to 2009, the authors try - to the greatest extent possible - to replicate the results from the CREDO study for that state in aiming to employ alternative models to assess the sensitivity of 
the matching approach and thereby assess the robustness of non-experimental methodologies commonly used to measure charter school effectiveness. The authors contribute to validating the reliability of non-experimental study results in program evaluation in general, and the CREDO study in particular, and shed light on the reason why experimental and non-experimental research results in this field have differed systematically. Based on their findings, the authors point to several important contextual issues that require attention, for instance whether to include program indicators such as student participation in special education, free and reduced lunch and limited English proficiency programs in the matching process, and the need for sensitivity tests to avoid possible bias. Moreover, since they find significant performance differences between oversubscribed and undersubscribed charter schools, they argue that it is problematic to focus on the overall effectiveness of charter schools since the latter are often excluded from experimental studies.

In the fourth and final article, Faddar, Vanhoof and De Maeyer focus on instruments for school self-evaluation, in particular surveys of staff members, to gather information on the functioning of schools. During their study, they conducted interviews with 20 teachers and principals in four schools where they analysed respondents' cognitive processes when responding to items. Their answers were compared to descriptions of the items' intended meaning as formulated by the instrument developers. The findings demonstrate how difficult it is for respondents to respond to the complex reality reflected in the survey items. Several problems arise, as the respondents are required to interpret and elaborate on item formulations, and on the process of selecting an answer option that corresponds to their mental judgement. Moreover, the authors also find that the position the respondents hold in the school organisation influences some aspects of their answering process. The authors raise questions with respect to validity, and they argue for investing in improving and revising survey instruments and for considering ways of adequately using these instruments, which requires an accurate understanding of the survey and the results.

\section{Reflections and questions for further discussion}

We would like to draw your attention to three points. The first point relates to school inspections as a way of governing education quality and the accompanying accountability processes. Kemethofer et al. describe how school inspection procedures changed in Austria and Sweden about 10 years ago. In many ways, the current form of school inspection can include elements of both the traditional and modernised ways of conducting school inspections. Related to other approaches, the school inspection retains its distinctive features as a governing mode. According to Ozga et al. (2013), it first includes direct observations of sites and practices where inspectors are empowered by educational authorities to enter the world of schools, which is also why school inspection is characterised as governing at a distance. Second, it includes a form of qualitative evaluation involving the exercise of judgement. Third, it represents embodied evaluation, since the presence of an inspector who embodies certain required types of knowledge, judgement and authority is required at the site. However, it is important to remember that in the current forms of school inspection, the observations and qualitative judgements take place according to standards and benchmarks aiming to 
come up with targeted areas for improvement. This means that it is questionable what kind of agency the school inspector has to exercise judgement. In the case of Austria and Sweden, it is interesting that the authors find that in a governing context with a greater degree of accountability pressure, school inspection, seen from the perspective of the principals in terms of formulated standards known to the principals, has a greater effect than in a governing context with less pressure. With respect to the effect of feedback in terms of an inspection report, the situation is the opposite. An interesting area for further investigation could be to analyse the actual content of the feedback reports to determine if this is communicated in different ways.

The second point is related to the article of Ehren and Godfrey and the challenges with regard to a standardised inspection framework and further development of MAT in the English context. They argue that further development of the networks requires local stakeholders' accounts and accountabilities within the network. In other words, this means that further development necessitates governing by means of close relationships, rather than governing at a distance.

The third point is related to methodological concerns in both internal and external evaluations and the implications in terms of bias and misinterpretation of the results. Faddar et al. argue that quality assurance of survey instruments used in schools' selfevaluations is needed. Ackerman and Egalite address several important issues that need to be taken into consideration when evaluating the effectiveness of charter schools. Regarding charter schools, it could also be added that when there is so much at stake politically, methodological awareness is even more important in ensuring that evaluations do not produce results that are misleading or can be easily misinterpreted.

\section{References}

Ozga, J., Baxter, J., Clarke, J., Grek, S., \& Lawn, M. (2013). The politics of educational change: governance and school inspection in England and Scotland. Swiss Journal of Sociology, 39(2), 205-224.

Ozga, J., Dahler-Larsen, P., Segerholm, C., \& Simola, H. (Eds.). (2011). Fabricating quality in education: data and governance in Europe. London: Routledge.

Spillane, J. (2012). Data in practice: conceptualizing the data-based decision-making phenomena. American Journal of Education, 118(2), 113-141.

Mausethagen, S., Prøitz, T. S., \& Skedsmo, G. (2017). Teachers’ use of knowledge sources in result meetings': Thin data and thick data use. Teachers and Teaching: Theory and Practice. https://doi.org/10.1080 /13540602.2017.1379986 